\title{
Geopolymers Supported on Inert Substrate for Phosphate Removal from Natural Waters
}

\author{
Tatiana Samarina $^{1}$, Esther Takaluoma ${ }^{1}$, Aizan Kazmaganbetova ${ }^{2}$ \\ ${ }^{1}$ Kajaani University of Applied Sciences \\ Ketunpolku 1, PL 52, 87101, Kajaani, Finland \\ tatiana.samarina@kamk.fi; esther.takaluoma@kamk.fi \\ ${ }^{2}$ University of Tartu \\ Ülikooli 18, 50090, Tartu, Estonia \\ kzmgnb10@gmail.com
}

\begin{abstract}
The application of low-cost materials in wastewater treatment has recently aroused great interest. In here, we present inventive composite adsorbents prepared from industrial waste materials: biomass fly ash (FAF) and calcined paper mill sludge (FSHCa). To increase usability and decrease cost of adsorbent, the raw materials were loaded on the inorganic inert support with their simultaneous alkaline activation to confer the resulting composites new mechanical and adsorption properties. The ability of the new composite adsorbents to remove phosphate from diluted solutions was evaluated. All raw materials and composites have been characterized by XRF and XRD. The influence of waste material amount in the adsorbent composition, the adsorbent dose, and contact time on adsorption characteristics has been investigated at static conditions by batch adsorption experiments. For the best identified composition, the phosphate adsorption increases from $0.09 \mathrm{mg}-\mathrm{P} / \mathrm{g}$ for pure support material up to $7.6 \mathrm{mg}-\mathrm{P} / \mathrm{g}$ for composite with FAF geopolymer content of $20 \mathrm{wt}$. \% . The sorption process was relatively fast for FAF-based composite and equilibrium has been reached at $5 \mathrm{~h}$ contact time, while for FSHCa-based composite an equilibrium has been reached only at 28 hours. The maximum removal percentage, 98\%, was achieved at an adsorbent loading weight of $5 \mathrm{~g} / \mathrm{L}$ for FAF-based composite whereas the removal rate for FSHCabased composite was only $34 \%$ under the batch test conditions. The optimized method was applied for phosphate removal from river and lake waters. The achieved phosphate removal efficiency was $92 \%$ and $36 \%$ using FAF- and FSHCa- compositions, respectively. As raw materials contain from 47 to $75 \%$ of $\mathrm{CaO}$, the phosphate appears to precipitate in form of hydroxyapatite on the adsorbent surface.
\end{abstract}

Keywords: Adsorption; Geopolymer Composite; Supported Adsorbent; Phosphate Removal.

\section{Introduction}

Phosphorus (P) in its different forms is an essential element for all living organisms and key non-replaceable nutrient in modern agronomy [1]. In 2014, EU placed phosphate rock on the list of critical raw materials. Since then, recycling of $P$ has become a more and more attractive option in terms of economic importance and market supply potential [2]-[4].

However, leaching of fertilizers from agricultural crop production results into redundant concentration of phosphate in run-off water [5]. Ending up in water bodies, phosphorus entails eutrophication problems, which, in turn, cause a number of issues from declining recreational potential of water bodies to reduction of biological diversity [6]. To close the nutrient loop, new and innovative ways for more efficient phosphorus cycling are therefore urgently necessary. The development of nutrient recovery and reuse technologies is beneficial as for environment protection by mitigation of negative effects on water bodies, yet for using recovered substances for production of useful materials, e.g. fertilizers or soil amendments [7].

In this work, we present the development of low-cost composite adsorbents for phosphate removal. The work objectives are to find an efficient way of adsorbent production utilizing industrial by-products and to increase final products usability as compared with raw materials. The products obtained should have high capacity and selectivity towards phosphate ions, on the one hand, but possessing unique properties and ease of manufacturing on the other. Light expanded clay aggregate (LECA) was chosen as a substrate material enabling to bring lightweight and floating properties to new composites. Despite the fact that LECA have been investigated previously as adsorptive material for nutrient 
removal [8], the efficiency and adsorption capacity of the raw material are low. Thus, the modification of the LECA surface with metal oxides was required to enhance the adsorption of P on LECA [9].

For the first time, we propose the combination of in-situ inorganic polymer formation (geopolymer, GP) to increase the P removal ability and the unique physical properties of LECA. A new approach to manufacturing of adsorbents is being applied to gain new properties (porosity, lightness, ability to float) and/or to reduce production cost. Results aim at creating environmentally friendly and economically favourable GP-composites, complying with the requirements of circular economy concept.

\section{Materials and methods}

\subsection{Materials}

Phosphoric acid (85\%) and sodium hydroxide were purchased from VWR Chemicals. Sodium silicate - ZEOPOL 25 (42-46\%, molar ratio $\mathrm{SiO}_{2}: \mathrm{Na}_{2} \mathrm{O}$ is 2.4-2.6) was purchased from JV Huber. The paper mill sludge with high calcium content (FSHCa) was preliminarily dried at room temperature for several days, and then the fibre particles contained in the sludge were ignited at $750^{\circ} \mathrm{C}$ for several hours. Fly ash F (FAF) was obtained from UPM in form of fine powder and used as received. Light expanded clay aggregate (LECA) was purchased from local store and sieved to fractions 1-2, 2-4, and 4-8 $\mathrm{mm}$ prior use.

\subsection{Geopolymer composite preparation}

Supported geopolymers were prepared by mixing of $500 \mathrm{~g} \mathrm{LECA}$ with alkaline activator in Eirich laboratory mixer (type EL1), and a solid material (FAF or FSHCa) was added at the last stage. Alkaline activator contained 8M sodium hydroxide and sodium silicate in a weight ratio of 1.2. The mixtures were allowed to consolidate at ambient temperature for three days, and the granules with supported geopolymers were sieved and washed with deionized water until $\mathrm{pH} 7.8$. Fractions with particle size of 1-2 $\mathrm{mm}$ and 2-4 mm were used for batch and fixed-bed continuous adsorption experiments.

Modifications of geopolymer preparation included type of raw material, ratio of liquid and of solid components are presented in Table 1. Thus, the code of composite 100LECA100FAF means that this particular supported geopolymer was prepared with $8 \mathrm{M} \mathrm{NaOH}$, solid material contained $100 \mathrm{~g}$ of alkaline activator and $100 \mathrm{~g}$ of FAF, respectively.

\subsection{Adsorption experiment}

The adsorption experiments were performed using batch equilibration and fixed-bed continuous method. In the batch method, a portion of adsorbent $\left(5 \mathrm{~g} \mathrm{~L}^{-1}\right.$, fraction $2-4 \mathrm{~mm}$ ) was agitated with $200 \mathrm{ml}$ solution contained phosphorous as phosphate (overhead shaker) at room temperature for the desired time period to reach equilibrium. The effect of initial ion concentration and contact time on removal of phosphate was studied by keeping other factors as constant. After filtration though paper filter (pore diameter $2.5 \mu \mathrm{m}$ ), phosphate concentrations were determined according EPA Method 365.3 by UV-Vis spectrophotometry.

Continuous experiments were performed by pumping samples of synthetic, natural or municipal wastewater at flow rate $0.3 \mathrm{~L} / \mathrm{h}$ through the column filled with $100 \mathrm{~g}$ of geopolymer granules. The breakthrough points were established at $0.05 \mathrm{C} / \mathrm{C}_{0}$, yet a full saturation time at $0.95 \mathrm{C} / \mathrm{C}_{0}$. The phosphorous concentration in effluents was determined at regular time intervals and the obtained breakthrough curves were used for results interpretation.

Table 1: Variation of a geopolymer synthetic procedure and parameters tested in preliminary batch experiments (adsorbent dose $5 \mathrm{~g} \mathrm{~L}^{-1}$, contact time 24h).

\begin{tabular}{|l|c|c|}
\hline \multicolumn{1}{|c|}{ Composite } & FAF & FSHCa \\
Parameter & $6-12 \mathrm{M}$ & $6-12 \mathrm{M}$ \\
\hline NaOH molarity & $25-200$ & $25-100$ \\
\hline Solid material & $35-100$ & $25-80$ \\
\hline Alkaline activator & 10 and $50 \mathrm{mg} \mathrm{L}^{-1}$ & 10 and $50 \mathrm{mg} \mathrm{L}^{-1}$ \\
\hline Phosphate concentration
\end{tabular}




\section{Results and Discussion}

In this study, for the first time composite geopolymer materials are designed and applied for phosphate removal from drinking and natural waters. For this purpose, the series of adsorbent compositions employing industrial solid wastes such as FAF and FSHCa were chosen as raw materials to be a primary source of $\mathrm{Ca}, \mathrm{Al}$ and $\mathrm{Si}$ for alkaline activation technique (geopolymerization). To decrease a production cost of adsorptive media by geopolymerization, light expanded clay aggregate (LECA) was used as an inert supportive material possessing a number of unique properties (porosity, nontoxicity, light in weight, buoyancy). The effect of ratios alkaline activator-inert support and alkaline activator-supported materials on adsorption capacities obtained geopolymer composites was investigated. The maximum content of waste materials used for composite preparation was $20 \mathrm{wt}$. \%. At higher FAF or FSHCa contents, the GP-composites crumbled and obtaining of reliable data was inconvenient. A larger amount of alkaline activator led to getting heavier the GPcomposites and, consequently, to a loss of ability to float.

The composites with FSHCa do not show high adsorption capacities at preliminary experiments $(0.2-1.3 \mathrm{mg} \mathrm{P} / \mathrm{g})$. Capacities at phosphate concentration of $50 \mathrm{mg} / \mathrm{L}$ are $7.0 \mathrm{mg}$ P/g for the best LECA-FAF-GP composition (55 g alkaline activator and $100 \mathrm{~g}$ FAF per $500 \mathrm{~g}$ LECA), $1.3 \mathrm{mg}$ P/g for LECA-FSHCa-GP, and $0.09 \mathrm{mg}$ P/g for LECA, respectively. A removal rate over $98 \%$ was achieved with an adsorbent dose of $5 \mathrm{~g} / \mathrm{L}$ for LECA-FAF-GP while only $34 \%$ of phosphate was removed by LECA-FSHCa-GP at the same dosage. Thus, only supported adsorbents with FAF were used for further investigation (Table 2).

Table 2: Adsorption capacity of obtained composites at different component ratios.

\begin{tabular}{|l|c|c|c|}
\hline Pample code & $\begin{array}{c}\text { Alkaline } \\
\text { activator, } \mathrm{g}\end{array}$ & FAF, $\mathrm{g}$ & $\begin{array}{c}\text { Adsorption } \\
\text { capacity, mg P /g }\end{array}$ \\
\hline 35LECA100FAF & 35 & 100 & 7.6 \\
\hline 55LECA100FAF & 55 & 100 & 7.1 \\
\hline 85LECA100FAF & 85 & 100 & 1.6 \\
\hline 100LECA100FAF & 100 & 100 & 1.4 \\
\hline 125LECA100FAF & 125 & 100 & 2.2 \\
\hline 55LECA25FAF & 55 & 25 & 1.2 \\
\hline 55LECA35FAF & 55 & 35 & 3.3 \\
\hline 55LECA45FAF & 55 & 45 & 2.8 \\
\hline 55LECA60FAF & 55 & 60 & 3.3 \\
\hline 55LECA100FAF & 55 & 100 & 7.0 \\
\hline
\end{tabular}

For all composites, the ability to float is shown (Fig.1). However, at high FAF or FSHCa contents, solid materials are partially came loose and ended up in aqueous phase due to incomplete reaction of geopolymerization. The use of larger quantities of alkaline activator leads to lose the ability of granules to float. Nevertheless, this approach can still be used to decrease a cost of granulated geopolymers.

Fixed-bed continuous column experiments were carried out for LECA-FAF-GP prepared with different amount of alkaline activator. Granules with the size distribution 4-8 $\mathrm{mm}$ were loaded into adsorption tower with a counter-current flow scheme, and the influence of flow rates and adsorptive layer length on operational conditions was evaluated. Two samples of natural waters were treated in bench scale application at the static and dynamic conditions. Both water samples were spiked with $10 \mathrm{mg} / \mathrm{L}$ of phosphate and showed removal rates of at least $95 \%$ in batch experiments. In continuous column experiment, more than 65 hours of operational time $\left(0.95 \mathrm{C} / \mathrm{C}_{0}\right)$ were reached for LECA-FAF-GP with FAF content 15 wt.\% (55LECA100FAF). 


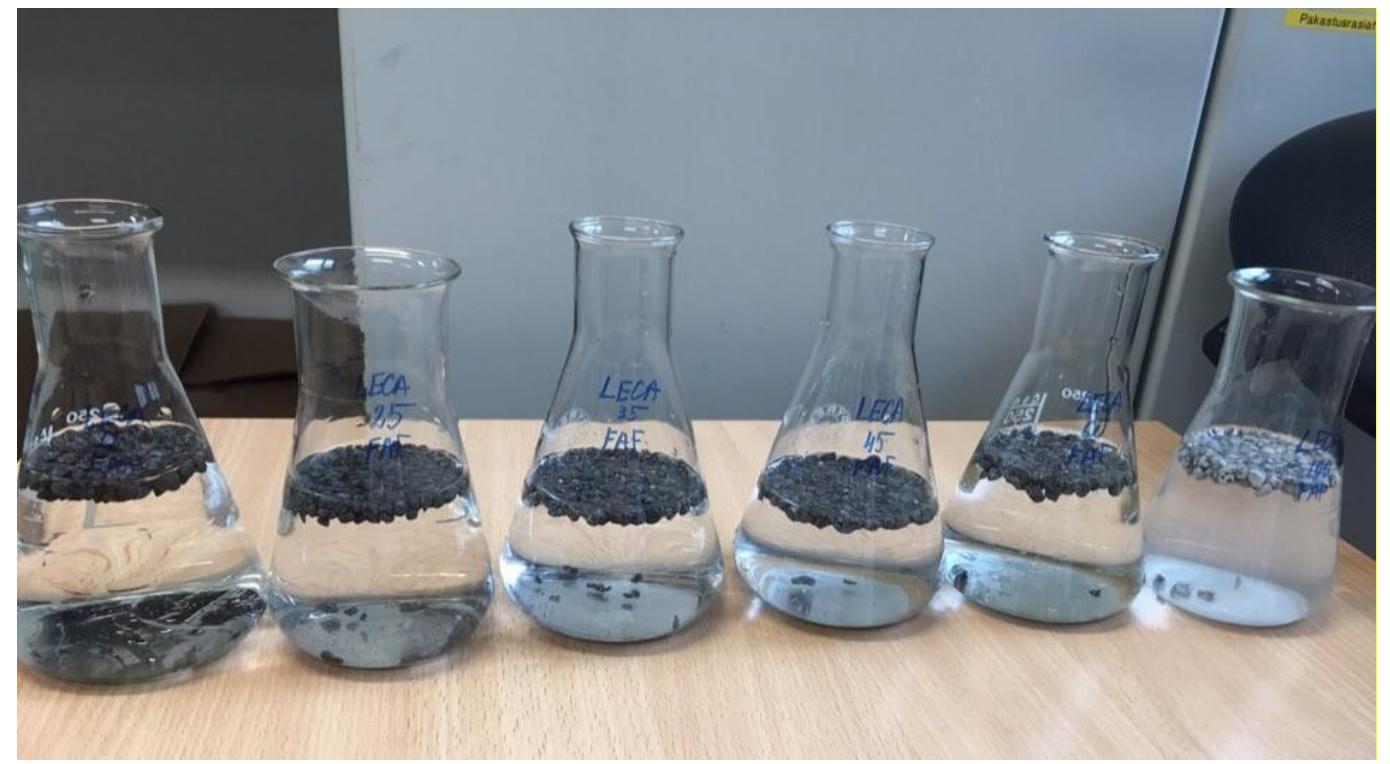

Fig. 1: Demonstration of floating properties of obtained composites.

\section{Conclusion}

An innovative and simple way to produce new supported geopolymer adsorbents were examined. It was found that LECA-FAF-GP has better performance characteristics than LECA-FSHCa-GP in terms of time of adsorption and adsorption capacity. The tentative estimation of production cost has shown possible diminish of price up to 12 times to compare with granulated FAF-GP without support material. The adsorbents enriched with phosphorus have a great potential to be recovered and reused as a fertilizer or amendment agent since non-toxic support was used.

\section{Acknowledgements}

This study was conducted as part of the WaterPro project (number A74635 EAKR, Keski-Pohjanmaan Liitto/Kainuun Liitto/Pohjois-Pohjanmaan liitto) with the support of Maa- ja vesitekniikan tuki (№ 13-8271-17).

\section{References}

[1] Phosphorous in global environment (SCOPE 54). H. Tiessen, Ed., Chichester: Wiley, 1995.

[2] H. Ohtake and S. Tsuneda, Phosphorus Recovery and Recycling. Singapore: Springer, 2018.

[3] P. Baumann, "Phosphorus removal: An economic assessment," in Phosphorus: Polluter and Resource of the Future Removal and Recovery from Wastewater, C. Schaum, Ed. International Water Association, 2018, pp. 205-218.

[4] P. Ghisellini, C. Cialani, and S. Ulgiati, "A review on circular economy: the expected transition to a balanced interplay of environmental and economic systems," J. Clean. Prod., vol. 114, pp. 11-32, 2016.

[5] G. Schroth and F. L.Sinclair, Trees, crops and soil fertility: concepts and research methods. Wallingford: CABI, 2002.

[6] M. Farley, "Eutrophication in Fresh Waters: An International Review," in Encyclopedia of Lakes and Reservoirs, L. Bengtsson, R. W. Herschy, and R. W. Fairbridge, Eds. Dordrecht: Springer Netherlands, 2012, pp. 258-270.

[7] J. M. Lema and S. S. Martinez, Innovative Wastewater Treatment \& Resource Recovery Technologies: Impacts on Energy, Economy and Environment. IWA Publishing, 2017.

[8] S. Sharifnia, M. A. Khadivi, T. Shojaeimehr, and Y. Shavisi, "Characterization, isotherm and kinetic studies for ammonium ion adsorption by light expanded clay aggregate (LECA)," J. Saudi Chem. Soc., vol. 20, pp. S342-S35.

[9] N. Yaghi and H. Hartikainen, "Enhancement of phosphorus sorption onto light expanded clay aggregates by means of aluminum and iron oxide coatings," Chemosphere, vol. 93, no. 9, pp. 1879-1886, 2013. 